\title{
SMALL BOWEL OBSTRUCTION DUE TO FOREIGN BODY INGESTION IN AN AUTISTIC CHILD
}

Rajesh Poudel, ${ }^{1}$ Samir Shrestha ${ }^{2}$

\section{ABSTRACT}

The pica phenomenon is common in patients with behavioral and developmental disorders, particularly autism. Most ingested foreign bodies pass through the gastrointestinal system spontaneously and without complication. Small bowel obstruction is an uncommon complication of ingested foreign body. Herein, we present the case of an autistic child who was operated for peritonitis due to an unusual foreign body.

KEYWORDS Autism, Foreign body, Ingestion, Obstruction

1. Department of Surgery, Universal College of Medical Sciences and Teaching hospital, Bhairahawha, Nepal

2. Department of Surgery, Patan Academy of Health Sciences, Patan, Nepal

DOI: http//doi.org/10.3126/jucms.v7i2.27146

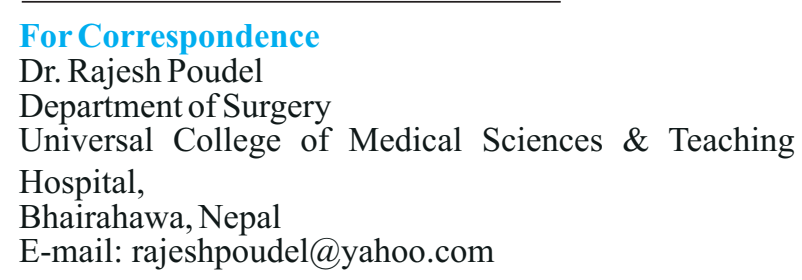




\section{INTRODUCTION}

Foreign body ingestion is frequently encountered in the pediatric population, mostly between the ages of six months and three years. ${ }^{1}$ The pica phenomenon, where non-edible substances are repeatedly consumed, is a well recognized phenomenon in patients with behavioral and developmental disorders, particularly autism. Small bowel obstruction is an uncommon complication of ingested foreign body because the foreign body passes spontaneously once it enters the small intestine. ${ }^{2}$ We present the case of an autistic child who was operated for peritonitis due to an unusual foreign body.

\section{CASE REPORT}

Eight years old girl with developmental delay and autism was presented to emergency department of Patan Hospital, Lalitpur, Nepal with complain of pain abdomen and vomiting for nine days. Because of her condition she was unable to communicate verbally. She had visited nearby hospital seven days back for same reason, where she was managed conservatively and discharged on oral medication. On examination her heart rate was 100 beats per minute. Blood pressure, temperature, respiratory rate were within normal limit. Her abdomen was distended; tender at all quadrant and percussion tenderness was present. There was a palpable intraabdominal lump in umbilical region of about 4 X $4 \mathrm{~cm}$, nonmobile, tender, smooth surface with irregular margin. Bowel sound was sluggish. White blood cell count was $19000 / \mathrm{mm}^{3}$. Urea, creatinine and electrolytes were within normal limit. Xray abdomen was done which showed a metal clip in right lower quadrant of the abdomen (Fig 1). Diagnosis of peritonitis with foreign body ingestion was made and planned for surgery. Emergency exploratory laparotomy was done. Intraoperative findings were dense adhesion of small bowel with interloop collection of pus and foreign body (hanger clip) at the jejunum $25 \mathrm{~cm}$ distal from duodenojejunal junction (Fig $2,3)$. Adhesionolysis, drainage of pus with removal of foreign body with resection anastomosis of jejunum was done. Postoperative period was uneventful and patient was discharged on $10^{\text {th }}$ postoperative day.

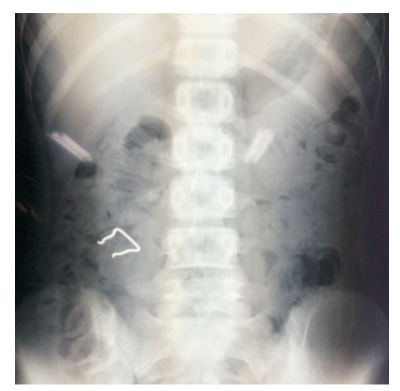

Figure 1. Metal clip in right lower quadrant of abdomen

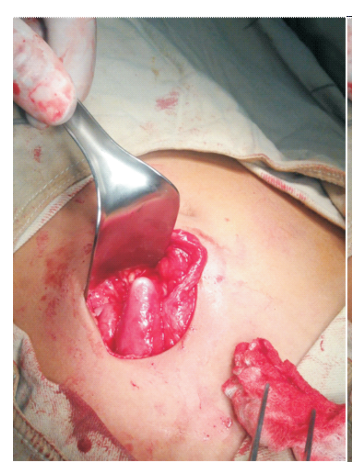

Figure 2. Impacted clip in the jejunum

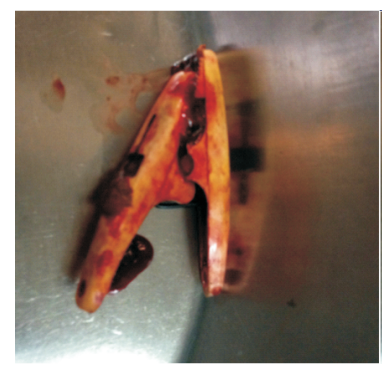

Figure 3. Retrieved hanger clip

\section{DISCUSSION}

Autism is a pervasive developmental disorder which was first described in 1943 by Leo Kanner, and is characterised by marked social and communication deficits. The prevalence for autism is estimated to be about 12 per 1,000 whilst approximately 6 per 1, 000 have autism spectrum disorders. ${ }^{3}$ Eating disorder in this type of patient is common.

Most ingested foreign bodies pass through the gastrointestinal system spontaneously and without complication. ${ }^{4,5}$ They may become impacted, most commonly at one of the sites of anatomic constriction in the oesophagus. ${ }^{6}$ The commonest site of impaction is in the upper oesophagus, at the level of the cricopharyngeus muscle, accounting for over $75 \%$ of all cases of foreign body impaction. ${ }^{7}$ Less frequently, objects may become impacted in the mid oesophagus at the level of the aortic arch or left main bronchus, or in the lower oesophagus at the gastro-oesophageal junction. ${ }^{8}$ Foreign bodies that pass beyond the gastro-oesophageal junction usually pass through the alimentary tract without complications. ${ }^{8}$ In fewer than $10 \%$ of cases, foreign bodies may impact within the intestines. ${ }^{9}$

In our case, patient had the habit of eating disorder. She was managed conservatively in other center for same cause and was discharged. She arrived in our emergency with features of intestinal obstruction and peritonitis. 
There are similar cases reported for foreign body ingestion with impaction in autistic child. ${ }^{10-13}$

Although the most common types of foreign bodies are metallic pieces, such as coins or pins, magnets, synthetic fibers or plastic objects. ${ }^{14,15}$ Ingestion of this kind of hanging clip is unusual.

\section{CONCLUSION}

Foreign body ingestion in child with autism is common. Because of the inability to communicate, there is likelihood of late presentation in case of impaction. High index of suspicion is required to diagnose and manage the complication.

\section{REFERENCES}

1. Wildhaber BE, Le Coultre C, Genin B. Ingestion of magnets: innocent in solitude, harmful in groups. Journal of Pediatric Surgery. 2005 Oct 1;40(10):e33-5.

2. Itagaki MW, Lema R, Gregory JS. Small bowel obstruction caused by a congenital jejuno-jejuno band in a child. Pediatric Emergency Care. 2005 Oct 1;21(10):673-4.

3. Newschaffer CJ, Croen LA, Daniels J, Giarelli E, Grether JK, Levy SE, Mandell DS, Miller LA, Pinto-Martin J, Reaven J, Reynolds AM. The epidemiology of autism spectrum disorders. Annu Rev Public Health. 2007 Apr 21;28:235-58.

4. Rodriguez H, Passali GC, Gregori D, Chinski A, Tiscornia C, Botto H, Nieto M, Zanetta A, Passali D, Cuestas G. Management of foreign bodies in the airway and oesophagus. International Journal of Pediatric Otorhinolaryngology. 2012 May 14;76:S8491.

5. Uyemura MC. Foreign body ingestion in children. American Family Physician. 2005 Jul 15;72(2).

6. Louie JP, Alpern ER, Windreich RM. Witnessed and unwitnessed esophageal foreign bodies in children. Pediatric Emergency Care. 2005 Sep 1;21(9):582-5.

7. Stack LB, Munter DW. Foreign bodies in the gastrointestinal tract. Emergency Medicine Clinics of North America. 1996 Aug;14(3):493-521.

8. A-Kader HH. Foreign body ingestion: children like to put objects in their mouth. World Journal of Pediatrics. 2010 Nov 1;6(4):30110.

9. Panieri E, Bass DH. The management of ingested foreign bodies in children--a review of 663 cases. European Journal of Emergency Medicine: official journal of the European Society for Emergency Medicine. 1995 Jun;2(2):83-7.

10. Rashid F, Davies L, Iftikhar SY. Magnetised intragastric foreign body collection and autism: an advice for carers and literature review. Autism. 2010 Mar;14(2):139-45.
11. Serour F, Witzling M, Frenkel-Laufer D, Gorenstein A. Intestinal obstruction in an autistic adolescent. Pediatric Emergency Care. 2008 Oct 1;24(10):688-90.

12. Narayanan PV, Balachandran MK. Colonic obstruction after ingested gravel and stone. Asian Journal of Surgery. 2012 Apr 1;35(2):96-8.

13. Singh A, Ganesan S, Pande S, Sridhar AV. Unusual cause of small bowel obstruction in an autistic child. BMJ case reports. $2012 \mathrm{Jul}$ 19;2012:bcr2012006400.

14. Wang PY, Skarsgard ED, Baker RJ. Carpet bezoar obstruction of the small intestine. Journal of Pediatric Surgery. 1996 Dec1 ;31(12):1691-3.

15. Chung JH, Kim JS, Song YT. Small bowel complication caused by magnetic foreign body ingestion of children: two case reports. Journal of Pediatric Surgery. 2003 Oct 1;38(10):1548-50. 